\title{
Avaliação química e nutricional do feijão carioca (Phaseolus vulgaris L.) cozido por diferentes métodos
}

\author{
Chemical and nutritional evaluation of Carioca beans (Phaseolus vulgaris L.) cooked by different methods
}

Taís Carolina Franqueira de TOLEDO ${ }^{1}$, Solange Guidolin CANNIATTI-BRAZACA ${ }^{1 *}$

\section{Resumo}

O objetivo dessa pesquisa foi avaliar alguns métodos de cocção em grãos de feijão (panela aberta, panela de pressão e microondas), utilizando ou não a maceração prévia dos grãos. Os resultados encontrados demonstraram que a ausência de maceração promoveu aumento no tempo de cocção das amostras, levando maior perda de nutrientes, aumento na digestibilidade in vitro da proteína e também inativação mais efetiva de taninos. A utilização de cocção em microondas preservou a disponibilidade dos aminoácidos lisina e metionina e apresentou valores maiores de fibras insolúveis. Maior teor de fibras solúveis foi obtido nas amostras que foram maceradas e quando a água de maceração foi utilizada.

Palavras-chave: feijão; cocção; maceração; panela de pressão; microondas.

\begin{abstract}
The aim of this study was to evaluate different methods to cook Carioca beans (open pan, domestic pressure cooker and microwave oven), with or without previous soaking of the beans. The results demonstrated that the absence of the soaking step promoted an increase in the cooking time of the samples, with a higher loss of nutrients, an increase of the in vitro protein digestibility and also a more effective inactivation of tannins. The use of the microwave oven preserved the availability of the amino acids lysine and methionine and presented higher values for insoluble fiber. Higher soluble fiber contents were found in the soaked samples when the soaking water was used.
\end{abstract}

Keywords: bean; cook; soaking; pressure cooker; microwave oven.

\section{Introdução}

No Brasil o feijão é a principal leguminosa fornecedora de proteínas para grande parte da população (ANTUNES et al., 1995).

Os grãos possuem de 20 a $35 \%$ de proteína, dependendo dos tratos culturais e da cultivar. O teor protéico e a produção são altos, porém, o valor nutritivo da proteína não é satisfatório por apresentar teores baixos de alguns aminoácidos essenciais limitantes. Esses aminoácidos são os sulfurados, a metionina, a cisteína e a cistina, além do triptofano. Também apresentam baixa digestibilidade, quando comparados às proteínas de origem animal (SGARBIERI, 1996).

Um dos fatores a interferir na baixa digestibilidade das proteínas do feijão cru é a presença dos inibidores de proteases. Embora estes pareçam ser geralmente inativados durante o cozimento, há relatos na literatura de atividade residual após o processamento desta leguminosa (EICHER; SATTERLEE, 1988) e também um outro fator seria a composição de suas proteínas.

Bressani (1993) apontou ser multicausal a reduzida digestibilidade das proteínas do feijão e de outras leguminosas, havendo além dos inibidores de proteases outros fatores ligados à casca (taninos), aos cotilédones (proteínas, taninos e fitatos), ao processamento e ao armazenamento. $\mathrm{O}$ ácido fítico é o ácido inositol 1,2,3,4,5,6-hexafosfato $\left(\mathrm{C}_{6} \mathrm{H}_{18} \mathrm{O}_{24} \mathrm{P}_{6}\right)$ (RIBEIRO; IDA; OLIVEIRA, 1999) e possui forte potencial quelante, podendo complexar-se com minerais, como cálcio, ferro e zinco, e com proteínas, comprometendo a digestibilidade das mesmas. Já os taninos são compostos fenólicos solúveis em água, com peso molecular variando entre 500 e 3000 D. Contêm muitos grupos hidroxila, que permitem a formação de ligações cruzadas estáveis com proteínas, o que reduz sua digestibilidade e conseqüente aproveitamento das mesmas pelo organismo animal (SILVA; SILVA, 1999; BARAMPAMA; SIMARD, 1994).

Quando armazenados em ambiente de alta umidade, e passando por longo tempo de cocção, por causa do endurecimento pós-colheita, os grãos de feijão apresentam redução do valor nutricional (ANTUNES; SGARBIERI, 1980). Além disso, as suas proteínas apresentam estrutura compacta, quando no estado nativo, o que as tornam resistentes à digestão (NIELSEN, 1991).

Diante dos fatos expostos, o objetivo do presente trabalho foi verificar as alterações na composição centesimal, lisina e metionina disponíveis, teor de antinutricionais, e na digestibilidade da proteína in vitro do feijão (Phaseolus vulgaris L.), comparando-se diferentes métodos de cocção (panela aberta, panela de pressão e microondas), utilizando-se feijões inteiros

Recebido para publicação em 23/1/2007

Aceito para publicação em 8/6/2007 (002143)

${ }^{1}$ Departamento de Agroindústria, Alimentos e Nutrição, Escola Superior de Agricultura Luiz de Queiroz - ESALQ, Universidade de São Paulo - USP, Av. Pádua Dias, 11, CP 9, CEP 13418-900, Piracicaba-SP, Brasil, E-mail: sgcbraza@esalq.usp.br

${ }^{*}$ A quem a correspondência deve ser enviada 
e macerados ou não, com e sem a utilização da água de maceração.

\section{Material e métodos}

\subsection{Material e preparo das amostras}

As análises foram realizadas no laboratório de Nutrição Humana e Alimentos da ESALQ/USP, e os grãos de feijão tipo Carioca safra agrícola ano 2002/2003 colhidos em maio de 2003, em único lote, e adquiridos em Sorocaba - SP/Brasil. Foram divididos nos seguintes tratamentos: T1: feijão sem maceração, cozido em panela aberta; T2: feijão sem maceração, cozido em panela de pressão; T3: feijão sem maceração, cozido em microondas; T4: feijão macerado, utilizando a água de maceração, cozido em panela aberta; T5: feijão macerado, utilizando a maceração, cozido em panela de pressão; T6: feijão macerado, utilizando a água de maceração, cozido em microondas; T7: feijão macerado, desprezada a água de maceração, cozido em panela aberta; T8: feijão macerado, desprezada a água de maceração, cozido em panela de pressão; T9: feijão macerado, desprezada a água de maceração, cozido em microondas. A quantidade de água utilizada é apresentada na Tabela 1.

\subsection{Análises químicas}

A análise da composição centesimal (matéria seca, cinza, proteína bruta, extrato etéreo, fibra alimentar solúvel e insolúvel) foi executada de acordo com a metodologia indicada pela AOAC (2006). Para a determinação de fibra solúvel e insolúvel foi realizada modificação utilizando solução de etanol a 95\%. O teor de fibra alimentar total foi obtido pela soma da fibra alimentar solúvel mais a insolúvel.

A digestibilidade da proteína in vitro foi determinada segundo metodologia descrita por Akeson e Stahmann (1964), a qual utiliza a digestão com as enzimas pepsina e pancreatina, seguida da precipitação das proteínas não digeridas com ácido pícrico, separação por centrifugação e quantificação por microkjeldahl (AOAC, 2006).

Os taninos foram determinados por método espectrofotométrico segundo metodologia descrita por Price et al. (1980) utilizando comprimento de onda de $500 \mathrm{~nm}$ para leitura. A de-

Tabela 1. Quantidade de água destilada utilizada na preparação das amostras para as etapas de cocção e maceração, sendo a quantidade de amostra utilizada para cada tratamento de $100 \mathrm{~g}$ de feijão.

\begin{tabular}{ccc}
\hline Tratamentos & Água de cocção $(\mathrm{mL})$ & Água de maceração $(\mathrm{mL})^{*}$ \\
\hline T1 & $1: 12$ & - \\
T2 & $1: 8$ & - \\
T3 & $1: 8$ & - \\
T4 & $1: 7$ & $1: 3$ \\
T5 & $1: 3$ & $1: 3$ \\
T6 & $1: 6$ & $1: 3$ \\
T7 & $1: 4$ & $1: 3$ \\
T8 & $1: 2$ & $1: 3$ \\
T9 & $1: 2$ & $1: 3$
\end{tabular}

${ }^{\star} \mathrm{O}$ tempo de maceração foi de 10 horas para todas as amostras. terminação de ácido fítico foi realizada por espectrofotometria segundo Grynspan e Cheryan (1989), com adição de reativo de Wade e com posterior leitura a $500 \mathrm{~nm}$.

Após a digestão das amostras, segundo Akeson e Stahmann (1964), as quantidades de lisina e metionina disponíveis foram quantificadas. A lisina foi determinada segundo Kakade e Liener (1969), por espectrofotometria, realizando leitura em comprimento de onda de $346 \mathrm{~nm}$, e a metionina disponível foi quantificada segundo Mc Carthy e Sullivan (1941) modificado por Lunder (1973) com determinação espectrofotométrica realizando a leitura em comprimento de onda de $510 \mathrm{~nm}$.

\subsection{Análise estatística}

Todas as análises químicas foram realizadas em triplicata. Para os resultados obtidos foi realizada a Análise de variância, o teste $F$ e posteriormente o teste de Tukey, quando o teste $F$ foi significativo ao nível de $5 \%$. Foi utilizado o programa estatístico SAS (1996) para a execução das análises.

\section{Resultados e discussão}

A Tabela 2 apresenta a composição centesimal dos grãos após os diferentes tratamentos.

De acordo com Barampama e Simard (1993), os teores de cinzas no feijão variam de 3,8 a 4,5\%, apresentando as amostras valores semelhantes (Tabela 2). Já Esteves (2000) encontrou valores de cinzas variando entre 3,98 e 4,47\% entre diferentes linhagens de feijão. Oliveira et al. (2001b) encontraram valores de $0,7 \%$ para grãos de feijão cozidos sem maceração. LeMessa (2004) estudando a influência de diferentes métodos tradicionais de processamento encontrou valores menores para os grãos que foram cozidos após maceração, concordando assim com os dados obtidos (Tabela 2). Esse autor apresenta valores de 3,3\% para os grãos cozidos e 1,6\% para os cozidos após maceração.

A utilização da água de maceração na cocção preservou em maior quantidade o teor de cinzas, pois a maceração causa a lixiviação de minerais (BARAMPAMA; SIMARD, 1995). Quando a água de maceração não foi desprezada os minerais solubilizados foram mantidos.

Costa et al. (2006) encontraram valor de 4\% de cinza em feijão macerado e cozido em panela de pressão na mesma água de maceração, valor este inferior ao encontrado na Tabela 2. Essa diferença pode ser devido à variação nos tratos culturais, local de plantio e cultivar dos grãos utilizados.

Segundo Esteves (2000), o conteúdo de proteínas do feijão em base seca situa-se entre 22 e $26 \%$, valores semelhantes aos encontrados no presente trabalho (de 20,35 a 27,24\%). No estudo realizado com feijão cozido em panela de pressão, realizado por Oliveira et al. (2001b), os valores encontrados para proteína foram de $19,8 \%$ para grãos de feijão cozidos sem maceração e 19,2 e 19,3\% para macerados e cozidos com e sem a água de maceração, respectivamente, não havendo diferença devido à substituição da água de maceração (OLIVEIRA et al., 2001a), como foi observado nos resultados obtidos (Tabela 2). 
Tabela 2. Composição Centesimal (\% em base seca) para os diferentes tratamentos de cocção dos grãos de feijão.

\begin{tabular}{|c|c|c|c|}
\hline Tratamento & Panela aberta & Panela de pressão & Microondas \\
\hline \multicolumn{4}{|l|}{ Cinza } \\
\hline Macerado, cozido na mesma água & $4,33 \pm 0,04^{\mathrm{aA}}$ & $4,58 \pm 0,05^{\mathrm{aA}}$ & $4,49 \pm 0,20^{\mathrm{aA}}$ \\
\hline \multicolumn{4}{|l|}{ Proteína } \\
\hline Sem maceração & $27,34 \pm 0,14^{\mathrm{aA}}$ & $25,06 \pm 0,10^{\mathrm{aB}}$ & $22,58 \pm 0,04^{\mathrm{bC}}$ \\
\hline \multicolumn{4}{|l|}{ Extrato etéreo } \\
\hline Sem maceração & $1,54 \pm 0,01^{\mathrm{aA}}$ & $1,68 \pm 0,01^{\mathrm{aA}}$ & $1,54 \pm 0,04^{\mathrm{aA}}$ \\
\hline Macerado, cozido na mesma água & $1,37 \pm 0,00^{\mathrm{bA}}$ & $1,28 \pm 0,13^{\mathrm{aA}}$ & $1,56 \pm 0,09^{\mathrm{aA}}$ \\
\hline Macerado, cozido em outra água & $1,65 \pm 002^{\mathrm{aA}}$ & $1,60 \pm 0,01^{\mathrm{aA}}$ & $1,31 \pm 0,02^{\mathrm{aA}}$ \\
\hline \multicolumn{4}{|l|}{ Fibra insolúvel } \\
\hline \multicolumn{4}{|l|}{ Fibra solúvel } \\
\hline Sem maceração & $9,83 \pm 0,05^{\mathrm{aA}}$ & $9,65 \pm 0,02^{\mathrm{bA}}$ & $4,82 \pm 0,20^{\mathrm{bB}}$ \\
\hline Macerado, cozido na mesma água & $7,90 \pm 0,09^{\mathrm{bB}}$ & $18,59 \pm 0,17^{\mathrm{aA}}$ & $9,25 \pm 0,16^{\mathrm{aB}}$ \\
\hline Macerado, cozido em outra água & $6,41 \pm 0,16^{\mathrm{cA}}$ & $5,04 \pm 0,46^{\mathrm{cAB}}$ & $3,13 \pm 0,23^{\mathrm{cB}}$ \\
\hline \multicolumn{4}{|l|}{ Fibra alimentar total ${ }^{4}$} \\
\hline Sem maceração & $46,04 \pm 0,20^{\mathrm{aA}}$ & $41,41 \pm 0,15^{\mathrm{bB}}$ & $46,86 \pm 0,48^{\mathrm{aA}}$ \\
\hline Macerado, cozido na mesma água & $46,61 \pm 0,43^{\mathrm{aAB}}$ & $48,56 \pm 0,43^{\mathrm{aA}}$ & $44,10 \pm 0,46^{\mathrm{bB}}$ \\
\hline Macerado, cozido em outra água & $41,63 \pm 0,42^{\mathrm{bB}}$ & $34,68 \pm 0,92^{\mathrm{cC}}$ & $44,45 \pm 0,49^{\mathrm{bA}}$ \\
\hline
\end{tabular}

No estudo de LeMessa (2004) a maceração não promoveu alterações na porcentagem de proteínas presentes, resultado semelhante ao encontrado no presente estudo. Costa et al. (2006) encontraram valores de $22,1 \%$ para grãos macerados e cozidos em panela de pressão mantendo a água de maceração.

Barampama e Simard (1993) encontraram valores de extrato etéreo variando entre 1,9 e 2,0\%, valores superiores aos encontrados no presente trabalho (de 1,31 a 1,68\%). O valor encontrado por Oliveira et al. (2001b) para grãos cozidos sem maceração foi de $2,5 \%$, que foi igual ao encontrado por Costa et al. (2006) para grãos cozidos em panela de pressão após maceração e cocção na água de maceração. A diferença entre os teores de extrato etéreo pode ser explicada pela diferença de cultivares, local de produção e tratos culturais. O teor de lipídios não variou com o tipo de cocção empregado, indicando que a pressão e as microondas não interferem no teor desse nutriente.

Para os valores de fibra insolúvel é possível observar que as amostras cozidas em forno microondas foram as que obtiveram maiores valores, quando as amostras não foram maceradas ou a água de maceração foi descartada.

Já o teor de fibra solúvel foi maior nas amostras maceradas quando a água de maceração foi utilizada e quando o cozimento foi realizado em panela aberta e de pressão.

Kuto, Golob e Plestnjak (2003) verificaram que o cozimento do feijão resulta em redução no teor de fibras insolúveis, sendo os valores encontrados de 23,3 e 22,6\% para feijão cru e cozido, respectivamente. Os autores ainda encontraram aumento do teor de fibras solúveis mediante maceração do feijão, antes de seu cozimento (o que só ocorreu quando a água de maceração foi utilizada na cocção em panela de pressão para o presente trabalho) e aumento no valor encontrado para fibra solúvel após o cozimento, sendo estes valores de 3,5\% para feijão cru e $5,9 \%$ para feijão cozido.

Gonzáles (2000) notou que os tratamentos térmicos podem ter efeitos variáveis na fibra alimentar, e que a cocção promove o rompimento dos componentes celulares dos grãos de feijão (celulose, hemicelulose, lignina, pectina e gomas), além de propiciar interações entre proteínas e lipídios, assim como trocas qualitativas e quantitativas que variam na composição total da fibra alimentar ao comparar alimento cru e cozido.

Costa et al. (2006) não observaram alteração dos teores de fibras solúveis e insolúveis antes e após cocção de grãos de feijão.

Quando a água de cocção foi desprezada ocorreu diminuição no teor de fibra alimentar total para todos os tipos de cocção, indicando que com a retirada da água de maceração ocorreu perda de parte desse elemento. A cocção em panela de pressão apresentou o menor valor para a fibra alimentar total, mostrando que a pressão e a alta temperatura alteram as estruturas das fibras e promovem maior degradação das mesmas. 
Avaliando os teores de aminoácidos disponíveis (Tabela 3) e considerando as diferentes formas de maceração, todas as amostras que foram maceradas apresentaram os maiores valores. As que tiveram sua água descartada apresentaram maior disponibilidade do aminoácido metionina, seguidas pelas amostras maceradas e por aquelas que tiveram essa água utilizada. As amostras sem maceração tiveram menor teor. Este fato pode ser explicado pelo maior tempo requerido para cocção nesse tratamento. Já com relação aos métodos, a cocção em microondas apresentou maior disponibilidade devido à diferente forma de energia empregada, já que estes aminoácidos têm grande sensibilidade a altas temperaturas. Helbig et al. (2003) avaliando a taxa de utilização da proteína em animais não encontrou diferenças entre feijões sem maceração, macerados e cozidos na mesma água e macerados ou cozidos com a troca da água de maceração.

Segundo Bressani et al. (1991), o aquecimento do feijão promove diminuição na disponibilidade de alguns aminoácidos, em particular a lisina, comprometendo sua qualidade como aminoácido complementar das proteínas dos cereais. Esse fato é atribuído à fusão dos polifenóis solúveis em água, que se difundem para dentro do cotilédone e reagem com as proteínas durante o aquecimento.

Para a digestibilidade da proteína (Tabela 4) não houve diferença significativa entre as amostras sem maceração e maceradas com a utilização da água, como contatado por Queiroz et al. (2002). Digestibilidade menor foi encontrada nas amostras maceradas e cozidas em outra água. Os tratamentos de cocção em diferentes formas não afetaram a digestibilidade das proteínas.

Os grãos que sofreram processo de maceração com a utilização da água para cocção, em comparação com os que não sofreram maceração, não apresentaram diferenças na digestibilidade de proteína medida in vivo (OLIVEIRA et al., 1999). Porém, quando a água de maceração foi substituída houve diferença na digestibilidade em relação aos grãos sem maceração quando foi utilizada panela aberta, e com utilização da água de maceração quando foi utilizada panela de pressão. Jood, Chauhan e Kappor (1989) e Barampama e Simard (1994) também encontraram diferenças de digestibilidade quando os grãos de feijão foram macerados ou não, provavelmente ligadas ao tempo de cocção aumentado para que ocorresse o amolecimento dos grãos.

Helbig et al. (2003) empregando cocção de grãos de feijão em panela de pressão e ensaio com animais, encontraram que o tratamento sem maceração apresentou a maior digestibilidade, concordando assim com os dados obtidos (Tabela 4).

Duarte (1995) estudou o efeito do caldo de cocção na qualidade protéica e observou que a eliminação do caldo de cocção não incrementou a qualidade protéica do feijão carioquinha, o mesmo foi constatado por Oliveira et al. (2001a,b). Quando se descartou a água de maceração e foi utilizado o método de cocção à pressão e microondas, no presente trabalho, houve diminuição na digestibilidade da proteína.

Os valores encontrados para a digestibilidade da proteína in vitro (de 69,33 a 82,59\%) estão de acordo com os valores encontrados por Marques e Lajolo (1981), que constataram que a cocção do feijão durante 30 minutos a $121{ }^{\circ} \mathrm{C}$ promoveu aumento na digestibilidade da proteína in vitro de 17 a $40 \%$ no feijão cru para 69 a $72 \%$ após o cozimento.

Eicher e Satterlee (1988) obtiveram resultado de 20,8\% para a digestibilidade de feijão cru. Sgarbieri e Whitaker (1982) acrescentam ser baixo o valor biológico das proteínas do feijão, quando comparado com o de outros alimentos. Quando Fukuda et al. (1982) determinaram a digestibilidade aparente do feijão cozido, os valores encontrados variaram entre 65,6 e 66,7\%. Segundo estes autores, a cocção do feijão não somente produz

Tabela 3. Valores dos aminoácidos disponíveis dos diferentes tratamentos de cocção em grãos de feijão, em mg de aminoácido/grama de amostra seca.

\begin{tabular}{lccc}
\hline \multicolumn{1}{c}{ Tratamento } & Panela aberta & Panela de pressão & Microondas \\
\hline \multicolumn{1}{c}{ Metionina } & & & $1,87 \pm 0,02^{\mathrm{cA}}$ \\
\hline Sem maceração & $1,37 \pm 0,01^{1 \mathrm{c} 2 \mathrm{C} 3}$ & $1,70 \pm 0,03^{\mathrm{cB}}$ & $2,23 \pm 0,05^{\mathrm{bA}}$ \\
Macerado, cozido na mesma água & $1,75 \pm 0,05^{\mathrm{bC}}$ & $1,87 \pm 0,02^{\mathrm{bB}}$ & $3,11 \pm 0,13^{\mathrm{aA}}$ \\
Macerado, cozido em outra água & $1,98 \pm 0,02^{\mathrm{aC}}$ & $2,82 \pm 0,10^{\mathrm{aB}}$ & $70,87 \pm 0,06^{\mathrm{aA}}$ \\
\hline \multicolumn{1}{c}{ Lisina } & & $62,70 \pm 0,60^{\mathrm{aB}}$ & $52,20 \pm 0,13^{\mathrm{cA}}$ \\
Mem maceração & $38,13 \pm 0,20^{\mathrm{cC}}$ & $50,98 \pm 0,10^{\mathrm{cB}}$ & $56,03 \pm 0,12^{\mathrm{bA}}$ \\
Macerado, cozido na mesma água & $43,26 \pm 0,11^{\mathrm{bC}}$ & $55,00 \pm 0,27^{\mathrm{bB}}$ & \\
\hline
\end{tabular}

${ }^{1}$ Média \pm desvio padrão; ${ }^{2}$ letras minúsculas diferentes na vertical diferem entre si com nível de significância igual a $5 \%$, com relação à maceração utilizada; $\mathrm{e}^{3}$ letras maiúsculas diferentes na horizontal diferem entre si com nível de significância igual a 5\%, com relação ao método de cocção empregado.

Tabela 4. Valores médios de três repetições das análises de digestibilidade da proteína in vitro de proteína dos diferentes tratamentos de feijão, em g. $100 \mathrm{~g}^{-1}$ de amostra fresca.

\begin{tabular}{llcl}
\multicolumn{1}{c}{ Tratamento } & Panela aberta & Panela de pressão & Microondas \\
\hline Sem maceração & $82,59 \pm 1,08^{\mathrm{la} 2 \mathrm{~A} 3}$ & $75,89 \pm 1,42^{\mathrm{abA}}$ & $80,86 \pm 0,41^{\mathrm{aA}}$ \\
Macerado, cozido na mesma água & $78,55 \pm 2,03^{\mathrm{abA}}$ & $80,83 \pm 1,45^{\mathrm{aA}}$ & $79,91 \pm 1,64^{\mathrm{aA}}$ \\
Macerado, cozido em outra água & $77,72 \pm 1,69^{\mathrm{bA}}$ & $69,33 \pm 2,67^{\mathrm{bB}}$ & $74,50 \pm 2,23^{\mathrm{aAB}}$ \\
\hline
\end{tabular}

${ }^{1}$ Média \pm desvio padrão; ${ }^{2}$ letras minúsculas diferentes na vertical diferem entre si com nível de significância igual a $5 \%$, com relação à maceração utilizada; e ${ }^{3}$ letras maiúsculas diferentes na horizontal diferem entre si com nível de significância igual a 5\%, com relação ao método de cocção empregado. 
a destruição e a inativação de fatores antinutricionais, mas também afeta a estrutura da proteína, tornando-a mais digerível. Sathe e Salunkle (1981) acrescentam que o calor úmido melhora a digestibilidade das proteínas do feijão em relação ao calor seco.

Para o teor de taninos (Tabela 5), foi observado que o tratamento sem maceração foi o mais efetivo na diminuição dos mesmos, devido ao fato de ser maior o tempo de exposição das amostras ao calor para cocção.

Para o valor de ácido fítico (Tabela 5), a cocção em panela aberta proporcionou maior teor desse elemento com ou sem maceração. Lathia, Hoch e Kievernagel (1987) não encontraram alteração significativa no conteúdo de ácido fítico após maceração.

A maceração não afetou o conteúdo de fitatos como observado por Oliveira et al. (2001b).

Helbig et al. (2003), estudando os efeitos da maceração em grãos de feijão, encontraram redução significativa de fitatos com a maceração, porém, os teores de taninos não se reduziram com a maceração. Por outro lado, Oliveira et al. (2001a) encontraram redução de cerca de $1,7 \%$ de fitatos e $21,1 \%$ de taninos com maceração de grãos de feijão. Ocorreu diminuição (Tabela 5) para os tratamentos em panela de pressão e microondas para os teores de ácido fítico, e para taninos o tratamento que promoveu maior redução foi o que não utilizou a maceração.

\section{Conclusões}

De acordo com os resultados obtidos é possível concluir que a não utilização da maceração aumentou a digestibilidade da proteína in vitro e foi também mais efetiva na inativação de taninos. E que a utilização de cocção em microondas preservou mais a disponibilidade dos aminoácidos lisina e metionina.

\section{Referências bibliográficas}

AKESON, W. R.; STAHMANN, M. A. A pepsin pancreatin digest index of protein quality evaluation. The Journal of Nutrition, Philadelphia, v. 83, n. 3, p. 257-261, 1964.

ANTUNES, P. L.; SGARBIERI, V. C. Effect of heat treatment on the toxicity and nutritive value of dry bean (Phaseolus vulgaris var. Rosinha G2) proteins. Journal of Agricultural and Food Chemistry, Washington, v. 28, n. 5, p. 935-938, 1980.

ANTUNES, P. L. et al. Valor nutricional de feijão (Phaseolus vulgaris, L.), cultivares rico 23, carioca, piratã-1 e rosinha-g2. Revista Brasileira de Agrociência, Pelotas, v. 1, n. 1, p. 12-18, 1995.

AOAC - Association of Official Analytical Chemists. Official methods of Analysis. 18 ed. Washington DC USA, 2006.

BARAMPAMA, Z.; SIMARD, R. E. Nutrient composition, protein quality and antinutritional factors of some varieties of dry beans (Phaseolus vulgaris, L.) grown in Burundi. Food Chemistry, Oxford, v. 47, n. 2 , p. $15-67,1993$.

. Oligosaccharides, antinutritional factors and protein digestibility of dry beans as affected by processing. Journal of Food Science, Chicago, v. 59, n. 4, p. 833-838, 1994.

. Effects of soaking, cooking and fermentation on composition, in vitro starch digestibility and nutritive value of common beans. Plant Foods for Human Nutrition, Dordrecht, v. 48, n. 4 , p. 349-365, 1995.

BRESSANI, R. Grain quality of common beans. Food Reviews International, Phyladelphia, v. 9, n. 2, p. 237-297, 1993.

BRESSANI, R. et al. Evaluación de dos métodos para establecer el contenido de poli fenoles en frijol crudo y cocido, y efecto que estos provocan en la digestibilidad de la proteína. Archivos Latinoamericanos de Nutrición, Caracas, v. 16, n. 4, p. 569-583, 1991.

COSTA, G. E. A. et al. Chemical composition, dietary fibre and resistant starch contents of raw and cooked peã, common bean, chickpea and lentil legumes. Food Chemistry, Oxford, v. 94, n. 2, p. 327-330, 2006.

DUARTE, M. S. L. Efeito do tegumento e do Caldo de Cocção do Feijão na Qualidade Protéica. Viçosa, 1995. 52 p. Dissertação (Mestrado em Ciências e Tecnologia de Alimentos). Universidade Federal de Viçosa.

EICHER, N. J.; SATTERLEE, L. D. Nutritional quality of Great Northern bean proteins processed at varying $\mathrm{pH}$. Journal of Food Science, Chicago, v. 53, n. 4, p. 1139-1143, 1988.

ESTEVES, A. M. Comparação química e enzimática de seis linhagens de feijão (Phaseolus vulgaris L.) Lavras - MG, 2000. 55 p. Dissertação (Mestrado em Ciência de Alimentos). Universidade Federal de Lavras .

FUKUDA, G.; ELIAS, L. G.; BRESSANI, R. Significado de algunos factores anti fisiológicos y nutricionales en la evaluación biológica de diferentes cultivares de frijol comun (Phaseolus vulgaris).

Tabela 5. Valores médios de três repetições das análises de antinutricionais dos diferentes tratamentos de feijão, em mg de antinutricional/gr de amostra seca.

\begin{tabular}{lcrr}
\hline \multicolumn{1}{c}{ Tratamento } & Panela aberta & Panela de pressão & Microondas \\
\hline \multicolumn{1}{c}{ Taninos } & & & $0 \pm 0,00^{\mathrm{cA}}$ \\
\hline Sem maceração & $0 \pm 0,00^{1 \mathrm{c} 2 \mathrm{~A} 3}$ & $0 \pm 0,00^{\mathrm{cA}}$ & $0,35 \pm 0,00^{\mathrm{aA}}$ \\
Macerado, cozido na mesma água & $0,33 \pm 0,00^{\mathrm{aA}}$ & $0,05 \pm 0,00^{\mathrm{bB}}$ & $0,03 \pm 0,00^{\mathrm{bB}}$ \\
Macerado, cozido em outra água & $0,06 \pm 0,00^{\mathrm{bB}}$ & $0,29 \pm 0,01^{\mathrm{aA}}$ & $10,99 \pm 0,12^{\mathrm{bB}}$ \\
\hline \multicolumn{1}{c}{ Ácido fítico } & & & $12,69 \pm 0,13^{\mathrm{aC}}$ \\
Sem maceração & $13,38 \pm 0,03^{\mathrm{cA}}$ & $13,13 \pm 0,07^{\mathrm{bB}}$ & $10,55 \pm 0,07^{\mathrm{cC}}$ \\
Macerado, cozido na mesma água & $14,33 \pm 0,07^{\mathrm{aA}}$ & $12,47 \pm 0,09^{\mathrm{cB}}$ & $13,65 \pm 0,02^{\mathrm{bA}}$ \\
\hline
\end{tabular}

${ }^{1}$ Média \pm desvio padrão; ${ }^{2}$ letras minúsculas diferentes na vertical diferem entre si com nível de significância igual a $5 \%$, com relação à maceração utilizada; $\mathrm{e}^{3}$ letras maiúsculas diferentes na horizontal diferem entre si com nível de significância igual a 5\%, com relação ao método de cocção empregado. 
Archivos Latinoamericanos de Nutrición, Caracas, v. 32, n. 4, p. 945-960, 1982.

GONZÁLES, G. C. A. Efecto del tratamiento térmico sobre el contenido de fibra dietética total, soluble y insoluble en algunas leguminosas. Archivos Latinoamericanos de Nutrición, Caracas, v. 50, n. 3, p. 281-285, set. 2000.

GRYNSPAN F.; CHERYAN, M. Phytate-calcium interactions with soy protein. Journal of the American Oil Chemistry Society, New York, v. 66, n. 1, p. 93-97, 1989.

HELBIG, E. et al. Effect of soaking prior to cooking on the levels of phytate and tannin of the commom bean an the protein value. Journal of Nutritional Science and Vitaminology, Osaka, v. 49, n. 2, p. 81-86, 2003.

JOOD, S.; CHAUHAN, B. M.; KAPOOR, A. C. Protein digestibility (in vitro) of chickpea and blackgram seeds as affected by domestic processing and cooking. Plant Foods for Human Nutrition, Dordrecht, v. 39, n. 2, p. 149-154, 1999.

KAKADE, M. L.; LIERNER, I. E. Determination of available lysine in proteins. Analytical Biochemistry, San Diego, v. 27, n. 2, p. 273-180, 1969.

KUTO, T.; GOLOB, T.; PLESTNJAK, M. K. A. Dietary fiber Content of Dry and processed beans. Journal of Food Biochemistry, Oxford, v. 20, n. 2, p. 231-235, 2003.

LATHIA, D.; HOCH, G.; KIEVENAGEL, Y. Influence of phytate on in vitro digestibility of casein under physiological conditions. Plant Foods for Human Nutrition, Dordrecht, v. 37, n. 3, p. 229-255, 1987.

LEMESSA, F. Effects of traditional processing of haricot bean (Phaseolus vulgaris L.) on nutritional composition. Journal of Food Science and Technology, Mysore, v. 41, n. 1, p. 99-102, 2004.

LUNDER, T. L. An improved method for the colorimetric determination of methionine in acid hydrolysat of biological products. Industri Alimentari, Pinerolo, v. 12, n. 5, p. 94-98, 1973.

MARQUEZ, U. L.; LAJOLO, F. M. Composition and digestibility of albumins, globulins and glutelins from Phaseolus vulgaris. Journal of Agricultural and Food Chemistry, Washington, v. 29, n. 5, p. 1068-1074, 1981.

McCARTHY, T. E.; SULLIVAN, M. X. A new and highly specific colorimetric test for methionine. Journal of Biological Chemistry, Bethesda, v. 141, n. 33, p. 871-876, 1941.
NIELSEN, S. S. Digestibility of legume protein. Food Technology, Chicago, v. 45, n. 6, p. 112-114, 1991.

OLIVEIRA, A. C. et al. Uso doméstico da maceração e sem efeito no valor nutritivo do feijão comum (Phaseolus vulgaris, L.). Revista de Nutrição, Campinas, v. 12, n. 2, p. 191-195, 1999.

OLIVEIRA, A. C. et al. A eliminação da água não absorvida durante a maceração do feijão comum aumentou o ganho de peso em ratos. Revista de Nutrição, Campinas, v. 14, n. 2, p. 153-155, 2001 a.

. O processamento doméstico do feijão comum ocasionou uma redução nos fatores antinutricionais fitatos e taninos, no teor de amido e em fatores de flatulência rafinose, estaquiose e verbascose. Archivos Latinoamericanos de Nutrición, Caracas, v. 51, n. 3, p. 114-120, 2001b.

PRICE, M. L.; HAGERMAN, A. E.; BUTLER, L. G. Tannin content of cowpeas, chickpeas, pigeonpeas and mung beans. Journal of Agricultural and Food Chemistry, Washington, v. 28, n. 2, p. $459-461,1980$.

QUEIROZ, K. S. et al. Soaking the common bean in a domestic preparation reduced the contents of raffinose - type oligosaccharides but did not interfere with nutritive value. Journal of Nutritional Science and Vitaminology, Osaka, v. 48, n. 4, p. 283-289, 2002.

RIBEIRO, M. L. L.; IDA, E. I.; OLIVEIRA, M. C. N. Efeito da germinação de soja cv BR-13 e Paraná sobre ácido fítico, fósforo total e inibidores de tripsina. Pesquisa Agropecuária Brasileira, Brasília, v. 34, n. 1, p. 31-36, Jan. 1999.

SATHE, S. K.; SALUNKLE, D. K. Solubilization and electrophoretic characterization of the Great Northern bean (Phaseolus vulgaris, L.) proteins. Journal of Food Science, Chicago, v. 46, n. 25, p. 82-87, 1981.

SGARBIERI, V. C. Proteínas em alimentos protéicos: propriedades, degradações, modificações. São Paulo: Varela, 1996. p.184-229.

SGARBIERI, V. C.; WHITAKER, J. R. Physical, chemical and nutritional properties of common beans (Phaseolus) proteins. Advances Food Research, San Diego, v. 28, n. 3, p. 93-166, 1982.

SILVA, M. R.; SILVA, M. A. A. P. Aspectos nutricionais de fitatos e taninos. Revista de Nutrição, Campinas, v. 12, n. 1, p. 21-32, 1999.

STATISTICAL ANALYSIS SYSTEM INSTITUTE. Sas/Qc software: usage and reference. 2 ed. NC: Cary, 1996. 2v. (version 6). 